\title{
TECNOCIÊNCIA, PENSAMENTO E FORMAÇÃO NA EDUCAÇÃO SUPERIOR
}

\author{
Pedro Goergen*
}

\author{
Recebido: 12 jun. 2014
}

Aprovado: 31 jul. 2014

*Programa de Pós-Graduação em Educação da Universidade de Sorocaba. Sorocaba, SP, Brasil. E-mail: pedro.goergen@prof.uniso.br

Resumo: Este ensaio tem o propósito de refletir sobre a relação entre conhecimento, pensamento e formação, no contexto da educação superior. Ponto de partida é a relevância do uso intensivo da ciência e tecnologia para a vida social, política e econômica na sociedade contemporânea. Dentre as principais instituições encarregadas de desenvolver e difundir conhecimento e tecnologia encontram-se aquelas da área de educação superior. Elas assumem cada vez mais o discurso do conhecimento instrumental, útil e mercadológico, sem considerar seu lado controverso e obscuro, em termos sociais e históricos. Neste mesmo movimento, relegam a um segundo plano sua tarefa crítico-reflexiva e formativa das novas gerações. Pretendo chamar a atenção para esta realidade, defendendo a tese de que o pensamento crítico-transgressor é essencial ao processo formativo. E, em termos práticos, fundamental, também, da formação de docentes e estudantes.

Palavras-chave: Educação superior. Universidade. Ciência e tecnologia. Pensamento crítico. Formação docente.

\section{TECHNOSCIENCE, THOUGHT AND HIGHER EDUCATION LEARNING}

Abstract: This essay aims to reflect on the relationship between knowledge, thought and training in the context of higher education. The starting point is the relevance of the intensive use of science and technology for social, political and economic life in contemporary society. Among the main institutions responsible for developing and disseminating knowledge and technology are those in the area of higher education. They are increasingly taking the discourse of instrumental, useful and marketable knowledge, without regard to its controversial and obscure side, in social and historical terms. In this same movement, they relegate to the background its critical-reflective task of educating the new generations. I intend to draw attention to this reality, defending the thesis that critical-transgressive thinking is essential to the educational process. And in practical terms, also fundamental to the training of teachers and students.

Key words: Higher education; University; Science and technology; Critical Thinking; Teacher education. 
(WHITEHEAD).

Desbarbarizar tornou-se a questão mais urgente da educação hoje em dia

(ADORNO).

\section{INTRODUÇÃO}

Mesmo sendo fonte de todo o processo de hominização desde os primórdios de nossa espécie, o conhecimento nunca esteve tão estreitamente atrelado ao exercício do domínio e do poder quanto hoje. Tornou-se condição de acesso ao trabalho e de sobrevivência. Quanto mais conhecimento, melhores as perspectivas de desenvolvimento e ascensão social. Em função de sua sofisticação teórica e alto grau de especialização, a ampliação e a difusão da ciência e tecnologia foi assumida por instituições especializadas de acesso restrito. Por consequência, o poder inerente ao conhecimento passou a ser privilégio de poucos.

A universidade destaca-se como uma dos principais espaços de produção, organização e difusão de conhecimento. Distinta de outros agentes, tais como os grandes institutos nacionais ou internacionais de pesquisa, os laboratórios de empresas, as agências de pesquisa espacial etc., cabe à universidade, além da promoção e difusão do conhecimento, formar profissionais nas mais distintas áreas do conhecimento. Entre estes profissionais encontram-se os professores dos vários níveis do sistema educacional. Atribui-se a eles papel de destaque na construção de uma sociedade mais democrática, justa e de bem-estar.

Este sentido social, no entanto, contrasta, na perspectiva sistêmica, com as expectativas econômico-mercadológicas, favoráveis a uma ciência e formação instrumentais e úteis à produção e ao consumo, e, no nível privado, com os interesses profissionais individuais de renda e ascensão social. Registra-se, portanto, clara dissociação entre o desejado sentido social e o efetivo rumo mercadológico da educação superior. Conflitam interesses privados e expectativas sociais, hoje com forte predominância dos primeiros.

Partindo do pressuposto da inegável responsabilidade social da universidade no campo da geração e difusão do conhecimento, pretendo destacar a necessidade da formação crítico-reflexiva, isto é, do cultivo do pensamento 
como elemento central da educação superior. A intenção é mostrar, no quanto isto é possível num breve texto, que o pensamento crítico é condição tanto para uma compreensão mais aprofundada e coesa da própria razão humana, quanto para o desvelamento das tensões e contradições inerentes ao desenvolvimento científico-tecnológico contemporâneo. Esta dimensão formativa da educação superior me parece ser pressuposto incontornável da atuação socialmente responsável da universidade.

Divido minha exposição em três partes, iniciando com uma breve contextualização da evolução histórica das atividades acadêmicas de ensino e pesquisa rumo ao sentido instrumental-utilitarista, hoje prevalecente. Na sequência, faço algumas considerações sobre a centralidade do pensar como forma de romper a redução utilitarista e condição para a formação de cidadãos socialmente competentes e responsáveis. Finalmente, destaco a importância da formação docente enquanto estratégia de restauração do caráter reflexivo e pensante da educação superior.

De início, cabe-me assinalar uma importante dificuldade que pode relativizar a abrangência de minhas considerações. Refiro-me ao conjunto das instituições de educação superior no Brasil composto por $70 \%$ de instituições particulares/comerciais que atendem a $80 \%$ do total de alunos. Estas instituições, estritamente voltadas ao ensino e, em boa parte, vinculadas a grandes corporações que comercializam serviços educacionais, certamente consideram inócuas e extemporâneas as observações que farei a seguir. Seja como for e independente dessa realidade alarmante, considero importante que as instituições públicas e comunitárias ofereçam formação humana crítica, não limitada apenas aos estreitos limites sistêmico/instrumentais. Neste contexto, tomo a liberdade de usar indistintamente os termos universidade e educação superior. Do ponto de vista metodológico, sigo, em termos amplos, o referencial conceitual da teoria crítica, vinculada à postura crítica e dialógica.

\section{A UNIVERSIDADE APARELHADA}

No seu livro sobre o caráter unidimensional do homem e da sociedade contemporâneos, Marcuse (1973, p. 18) afirmou, em 1966, que "o aparato produtivo tende a tornar-se totalitário no quanto determina não só as oscilações, habilidades e atitudes socialmente necessárias, mas também as necessidades e aspirações individuais". Esta previsão efetivou-se nas décadas seguintes na medida em que a racionalidade científico-tecnológica se tornou o eixo condutor da sociedade contemporânea e suas instituições, inclusive as que atuam 
no campo da educação superior. Assim, a crescente confiança na eficácia dos controles tecnológicos como instrumentos de dominação torna-se também referência da racionalidade acadêmica. No espírito capitalista, especialmente no contexto neoliberal das últimas décadas, reforçou-se a tendência pragmático-econômica, contrária a qualquer transcendência.

De Agostinho a Tomás, os textos sagrados e a doutrina da Igreja eram os fundamentos da verdade. Em nome de poderes externos se exercia controle e dominação. Desde sua criação, no Século XI, a universidade assumiu, defendeu e ensinou estes princípios. Erasmo de Rotterdam e seus colegas humanistas ironizaram esta tradição no 'Elogio da loucura'e mudaram sua escrita, defendendo cidadania ao livre pensar, na passagem da Idade Média para a Moderna. Projetava-se uma nova ordem do pensamento, focada no conhecimento racional das regularidades regentes do mundo.

Na Idade Média, da qual a universidade era herdeira, a verdade se apoiava na autoridade filosófica ou teológica, enquanto a nova pesquisa, no início da modernidade, se abria ao futuro, livre de poder e domínio. Este novo mundo representava enorme desafio à universidade tradicionalmente ligada à Igreja e à tradição platônica dos valores transcendentais. Tradição ou inovação, fé ou razão, transcendência ou imanência eram os dilemas indicadores de novos rumos, aos quais a universidade não podia nem fechar nem escancarar as portas. Dois movimentos que, por tempos, ocorreram em paralelo, um fora, outro dentro da universidade.

Ao fazer uma comparação entre o Organum Aristotélico e Novum Organum de Francis Bacon, Reinhard Brandt (2011) mostra que, na acepção de Bacon, o interesse não mais recaía sobre o que é, mas sobre as propriedades daquilo que é. Esta nova lógica inclui e aceita a negação e a crítica como mecanismos próprios do conhecimento e progresso. A pesquisa volta-se para o novo, mostrando como as propriedades das coisas podem ser conhecidas, reproduzidas, ampliadas. Cada conhecimento novo representa um avanço em relação ao anterior, expondo-se, ao mesmo tempo, à crítica e à prova.

Estes procedimentos eram completamente desconhecidos na Idade Média com a qual a universidade ainda conservava forte relação. Explica-se, assim, porque grandes inovadores como Maquiavel, Grotius, Hobbes, Descartes, Gassendi, Malebranche, Locke, Leibnitz, Hume, Voltaire, Diderot, Rousseau e tantos outros não estavam ligados à universidade, embora houvesse também os que trabalhavam em universidades, como foi o caso de Melanchton, Newton, Spinoza, Mendelsohn, dentre outros. Importantes debates como o que se deu entre os 'antigos' e os 'modernos' (Querelle des anciens et des 
modernes - 1687-1715) ou projetos ambiciosos como o da Enciclopédia Francesa, liderado por Diderot e d'Alembert, não aconteceram na universidade. $\mathrm{Na}$ opinião de Brandt, o eventual desaparecimento da Universidade naquele momento histórico provavelmente teria passado desapercebido aos cientistas. O ensino e a aprendizagem na universidade continuavam voltados não à descoberta do novo, mas à explicação e preservação das doutrinas tradicionais. Nessa tensão se passaram os séculos do Humanismo/Renascimento.

Mudanças significativas aconteceram na primeira metade do Século XVIII a partir do Regulamento da Universidade de Göttingen que regimentalmente substituiu a ordem vertical por uma ordem horizontal e dialógica. Daquele momento em diante, a universidade passa a ser avaliada não pelo que ela é, mas pelos resultados que alavanca. Passa pelos umbrais da universidade o vento inovador de toda a Modernidade: o novo método, por Bacon chamado Novum Organum. Sua essência, formulada de maneira magistral na dúvida metódica de Descartes, resume-se no princípio, segundo o qual, a objetividade só se alcança pelo esforço sistemático do sujeito (BRANDT, 2011, p. 59). Pesquisa e conhecimento não consistem mais na eterna busca e explicação da verdade transcendente e imutável: ciência, crítica e esclarecimento buscam inovação e superação. Balizar o novo é o ideal que altera o cenário acadêmico a partir do Século XVIII, produzindo a mudança paradigmática da universidade tradicional para a universidade moderna. No entender de Brandt (p. 66),

pesquisa e ensino tornam-se agora os conceitos chave. A velha universidade não conhecia a pesquisa inovadora, mas se consagrava apenas à preservação de textos dogmáticos e, nas artes liberais, ao ensino de conhecimentos linguísticos e matemáticos.

Preparava-se, assim, a inovadora universidade de pesquisa do Séc. XIX, prenunciada no Conflito das Faculdades de 1798, no qual Kant (1993) assume que a humanidade deve orientar-se no futuro e não no passado. Até por volta de 1800, cabia às universidades apenas ensinar. Com a fundação da Universidade de Berlim, no século XIX, formou-se uma nova constelação acadêmica que, em termos gerais, sobrevive até hoje. Pesquisa e ensino se unem numa universidade estatal com o pretenso objetivo de fornecer formação humanística exemplar.

Com as mudanças ocorridas no final do Século XVIII, as universidades, até então a serviço do trono ou da Igreja, tornaram-se autônomas. Um cenário novo que levou Fichte, um crítico feroz do trono e do altar, ao cargo de catedrático da Universidade de Jena. No Século XIX, este modelo de universida- 
de alcançou enorme sucesso em todas as áreas do conhecimento. A estrutura disciplinar hierarquizada cedeu lugar a uma ordem horizontal, interdisciplinar e de conjunto, favorável ao desenvolvimento orgânico e criativo do conhecimento. Superar o já alcançado e produzir conhecimento novo anima a universidade. O triunfalismo controlador de Fichte cedeu lugar ao modelo plural das ciências individuais de Humboldt e Schleiermacher.

Elevou-se o status social dos catedráticos e as universidades passam a competir entre si para atrair as melhores cabeças. Sob a influência de Humboldt, a universidade alemã elabora um projeto que envolve três aspectos importantes: a formação dos funcionários públicos, em especial, de professores do ensino médio, a pesquisa nas ciências naturais e humanas e a formação dos jovens acadêmicos como cidadãos responsáveis. Tudo isso era mediado pela indissociabilidade entre Ensino, pesquisa e formação.

Este modelo difundiu-se pelo mundo ao longo do Século XIX e grande parte do Século XX. As universidades entendiam-se como centros de formação científica e cultural. As mudanças se aprofundaram ao longo do século XX, sobretudo, depois das duas grandes guerras mundiais, com forte incremento científico-tecnológico. Hoje há consenso em torno da tese de que o conhecimento se tornou o eixo central da vida social contemporânea. Conforma-se, assim, o que Bacon havia anunciado nos primórdios modernos do Sec. XVI: conhecer é saber.

$\mathrm{Na}$ verdade, o conhecimento é a fonte de liberdade, domínio e poder desde as primeiras comunidades humanas. Mas foram os cientistas dos séculos XVI e XVII e os iluministas do Séc. XVIII que elevaram ao extremo a crença no poder supremo da razão. Num movimento contínuo e cada vez mais acelerado, alcançamos hoje um momento de crise e inversão, de desconfiança e medo, frente a um sistema em que ciência e tecnologia assumem a magistratura da razão esclarecida, reduzindo o pensamento a uma pura aparelhagem matemática em que o factual tem a última palavra e o pensamento se transforma em mera repetição (ADORNO, 1995).

A imagem racional e mecanicista do mundo, criada na modernidade e elevada hoje ao absoluto da racionalidade, já não se sustenta frente à decepção provocada pelos impactos negativos da tecnociência. A produção de conhecimentos, as inovações tecnológicas e a difusão pelas redes de informação impulsionam a transformação que, de um lado, é o orgulho civilizatório e, de outro, o pavor da catástrofe e do regresso. Apesar de seus efeitos perversos, a atividade científica e suas inovações tecnológicas continuam transformando o mundo de forma impressionante. Paradoxalmente, no mesmo ritmo em 
que a humanidade parece aproximar-se da solução de seus problemas, cresce a ameaça da catástrofe. Nosso presente e futuro estão nas mãos da ciência e tecnologia, ironicamente, para o bem e para o mal.

Com isso, mais um paradigma festejado como absoluto alcança seus limites. As dúvidas e incertezas sinalizam uma nova ordem cujo fio condutor será compreender e assumir as responsabilidades frente aos impactos materiais e sociais do chamado progresso científico-tecnológico. Aos poucos, emerge em nossa consciência a necessidade de perguntar pelo sentido humano e social da ciência e tecnologia. Até o momento, a comunidade científica e as instituições dedicadas à produção de conhecimentos e à formação de pesquisadores ou profissionais de alto nível ainda pouco se preocupam com esta questão.

Se o mundo se produz e reproduz, se a vida depende da produção do conhecimento e de sua aplicação, é hora de refletir sobre as condições sob as quais se criam e usam os conhecimentos. As possibilidades de superação que ciência e tecnologia aportam não necessariamente são efetivadas como progresso. A respeito disso, Habermas (1997, p. 42) destaca que "embora a fome reine ainda sobre dois terços da população mundial, a eliminação da fome já não é nenhuma utopia no sentido negativo", mas constata também que "a emancipação relativamente à fome e à miséria não converge necessariamente com a libertação a respeito da servidão e da humilhação, pois não existe uma conexão evolutiva automática entre trabalho e interação". Trabalho economicamente produtivo e a interação socialmente justa são as duas dimensões do que se pode chamar de sentido e tarefa da Universidade.

No entanto, com o enquadramento da universidade na lógica do mercado, legitimada pela ideia de êxito, acabam-se a independência do pensamento e o poder de resistência crítica da universidade, cada vez mais subserviente às expectativas do mercado. Avesso a qualquer inconformismo não produtivo, $o$ aparato sistêmico impõe suas exigências econômicas como alternativa única de futuro. A ambivalência da universidade entre sua função sistêmica de desenvolvimento e difusão da tecnociência e o exercício crítico dos riscos deste roteiro foi assim definida por Marcuse (1973, p. 36):

Os setores mais avançados da sociedade industrial ostentam completamente estes dois fatores: a tendência para a consumação da racionalidade tecnológica e os esforços intensos para conter essa tendência no seio das instituições estabelecidas.

À universidade cabe recusar esta instrumentalização precisamente pela promoção de uma nova consciência enquanto 
espaço para a prática histórica transcendente, que está sendo barrado por uma sociedade na qual tanto os sujeitos como os objetos constituem instrumentos num todo que tem a sua razão de ser nas realizações de sua produtividade cada vez mais poderosa [na] aterradora harmonia entre liberdade e opressão, produtividade e destruição, crescimento e regressão (MARCUSE, 1973, p. 42 e 126).

Purgada da experiência negativa, a universidade é instada a abrir mão do seu poder e dever de negação: acomoda-se e fortalece a realidade estabelecida. E, ao acomodar-se, deixa de indicar alternativas, silencia frente à inclusão sistêmica do homem enquanto produto para a utilização técnica; aquietando-se, aceita a unidimensionalidade da realidade e suprime a contradição. Abre mão da locução política da socialidade ética, levada a termo pelo movimento subversivo e dialético do pensamento.

O pensamento crítico não teria 'per se' poder de transformação, mas seu exercício representa grande potencial formativo para aqueles que frequentam a universidade. Embora o pensamento opere sempre por abstração, não se trata aqui da abstração ao modo do idealismo platônico, do formalismo lógico de Aristóteles ou do idealismo kantiano. Trata-se, ao contrário, de uma abstração, por assim dizer, impura por não se dissociar do real, porquanto opera, conforme se expressa Marcuse (p. 135), "em bases históricas e permanece relacionada com as próprias bases das quais se inicia: o universo social estabelecido". As contradições do pensamento precisam refletir o complexo processo da sociedade e da natureza.

A universidade precisa, por um lado, pensar a totalidade e, por outro, acionar os mecanismos mediante os quais se produz e aplicam os conhecimentos, ou seja, assumir uma postura crítica frente à totalidade da humanidade e favorecer as ações humanas necessárias à vida. Nas palavras de Pérez Lindo (1998, p. 49),

o primeiro objetivo das instituições educativas e científicas é assumir o novo mundo e as novas ideias. Não para adaptar-se mimeticamente às mudanças. A educação sempre transcende o presente porque prepara para o futuro e, portanto, há que construir uma cosmovisão adequada e reelaborar o consenso intersubjetivo dos atores sobre o mundo que queremos.

Fins e identidade da universidade não devem seguir ideias idealistas preestabelecidas, mas emergir do contexto social, político, econômico e cultural, não para aparelhar-se a ele, mas para entender criticamente o presente e pen- 
sar o futuro. As ilusões com o saber científico, a explosão de conhecimentos e informações, as novas formas de produção e difusão dos conhecimentos, a aceleração das produções tecnológicas, as novas expectativas do mundo do trabalho e do mercado, o processo de globalização e/ou regionalização, a consolidação de um novo paradigma econômico fundado no uso intensivo do conhecimento, a fragmentação cultural e a segmentação social, o desenvolvimento da inteligência artificial, as dramáticas ameaças provenientes da exclusão social e da agressão ao meio ambiente são todos elementos de um cenário no qual a educação superior deve construir sua identidade. A partir do momento em que se torna uma instituição dependente de regulações pragmáticas, a universidade perde seu ideal de transcendência e submete-se à primazia instrumental.

Efetivamente, esta parece ser a grande preocupação da universidade contemporânea: servir da melhor forma possível ao sistema pela pesquisa e pelo ensino, pela produção e difusão de conhecimento instrumental, útil a aplicável. Imersas e atreladas às vertiginosas mudanças do mundo científico-tecnológico, as universidades se tornam reprodutivas do real, opacas ao pensamento. Como evitar que isso ocorra? Para ensaiar uma resposta a esta questão tentarei, como próximo passo, desenvolver uma reflexão sobre a importância do pensar enquanto consciência crítica.

\section{A EXPERIÊNCIA CRÍTICA DO PENSAR}

A universidade se vê tomada por um estilo comercial e político cujas formas de locução e comunicação são supostas como imunes ao protesto e à recusa. A unificação dos opostos leva a universidade a assumir a palavra da ordem estabelecida como acertada, tornando-se dele promotora e difusora. O caráter crescentemente unitário da linguagem acadêmica, adensada em torno do ser, revela seu paulatino encolhimento crítico. A economia de mercado, com sua formidável indústria de propaganda e convencimento, é metodicamente edulcorada como sistema promissor e sem alternativas para o futuro da humanidade. Pelo mesmo discurso se gera sub-reptícia familiaridade e plausibilidde da ideia de que a educação superior é um serviço/produto sujeito, como qualquer outro, aos ditames do mercado. 'Nossa economia', 'nosso sistema', 'nossa realidade' são expressões habilmente manejadas para juntar tecnologia, conhecimento, ensino e pesquisa num sentido único, acomodado e conjunto.

Marcuse (1973) chama isso de "comunicação funcional manipulada" promotora da identificação entre as pessoas, suas funções e o sistema. Excetuando 
algumas vozes dissonantes, vindas geralmente da área de ciências humanas, parece ser este o discurso hegemônico da universidade identificada com sua função sistêmica, esmagadoramente concretizada pela opinião manipulada (e economicamente recompensada) dos setores favorecidos da sociedade. Trata-se, na expressão, mais uma vez de Marcuse (p. 101), de uma "linguagem, que constantemente impinge imagens, milita contra o desenvolvimento e a expressão de conceitos. Em sua imediação e objetividade, impede o pensamento conceptual; impede assim o pensar".

A linguagem funcional rendida aos fatos, irreconciliavelmente anticrítica e antidialética, é essencial ao sistema, sua coordenação e aceitação, pois, sua natureza operacional e behaviorista absorve os elementos transcendentes, negativos e de oposição da razão. Fiel ao fato, ao número e ao dado, a linguagem funcionalizada, sem memória nem história, anula o potencial perturbador da razão. Na medida em que adere aos poderes instituídos, à verdade inconteste, à constatação do real, a universidade sucumbe à ritualização do discurso da ciência e da tecnologia.

Girando na órbita do real enrijecido, torna-se uma instituição autoritária que já não investiga num sentido amplo e desimpedido, mas assume e transmite aos seus estudantes, aristotelicamente, a lógica da verdade e da falsidade, inerente hoje à postura epistêmica da tecnociência. A exclusão da dimensão crítica do universo da racionalidade acadêmica representa a supressão de um de seus mais eminentes sentidos sociais: o exercício do pensamento crítico do ser, do presente, do dado, visando sua transformação qualitativa, ou seja, visando o 'dever ser'. Ora, o 'dever ser' não emerge do real, mas é fruto do trabalho do conceito, da transcendência.

Operar com conceitos significa, por sua vez, romper os limites da experiência imediata; significa transcender o espaço operacional, ultrapassar a aparência, trazendo à luz os lados obscuros do real. Não se trata de ascese idealista, mas de desconstrução da aparência pelo desvelamento da transcendência do verdadeiramente humano. Por isso, a realidade social sempre deve ser a referência da teoria e da prática, pois, nas palavras de Marcuse (1973, p 111), esta realidade

aparece sob outro aspecto se a sociedade em questão, conquanto permanecendo a estrutura de referência, se torna o objeto de uma teoria crítica que visa à própria estrutura dessa sociedade, presente em todos os fatos e condições particulares e determinando seu lugar e sua função. Então, seu caráter ideológico e político transparece, e a elaboração de conceitos adequadamente cognitivos exige o avanço além da concreção ilusória do empirismo positivista. 
O mundo é um mundo afligido pelo antagonismo entre contradição e harmonia, entre progresso e regressão, entre liberdade e servidão. Essas são as condições que determinam, de partida, a vida humana e a 'sociedade do conhecimento'. Para superar o negativo e melhorar as condições de vida de todos, existe o pensamento cujo sentido último é alcançar a convergência entre razão e liberdade. Este trabalho do conceito enfrenta a ideologia capitalista que, especialmente em sua atual fase neoliberal, investe massivamente na naturalização dos antagonismos entre o rico e o pobre, o culto e o ignorante, o incluído e o excluído como se fossem condições ontológicas das relações sociais. À universidade compete não andar de passo com esta postura, mas romper o círculo pétreo que opera a aterradora harmonia entre liberdade e opressão, produtividade e destruição, crescimento e regressão, social e subjetiva. Este é o trabalho da autonomia do pensar; dever e sentido da universidade.

Sempre se argumenta que a ciência é objetiva e neutra e que, portanto, ela se impõe pelas próprias regras da razão. Mesmo aceitando este argumento, não se pode esquecer que a razão teórica, ainda que pura e neutra, se coloca a serviço da razão prática. O sentido funcional dos conceitos da racionalidade científica se dissemina pela razão como um todo, contaminando de objetividade e utilidade o pensamento e o espírito. As fantásticas conquistas da ciência e tecnologia servem de argumento contra tudo o que não é operacional e útil. Num momento histórico em que prevalece o produto sobre a obra, os riscos da generalização da ideologia utilitarista precisam ser levados a sério. Marcuse (p. 160) anota que

a ciência, em virtude de seu método e de seus conceitos, projetou e promoveu um universo no qual a dominação da natureza permaneceu ligada à dominação do homem - uma ligação que tende a ser fatal para esse universo em seu todo. A natureza, cientificamente compreendida e dominada, reaparece no aparato técnico da produção e destruição que mantém e aprimora a vida dos indivíduos enquanto os subordina aos senhores do aparato. Assim, a hierarquia racional se funde com a social.

Não parece difícil demonstrar que esta é a tendência em curso na universidade. Cada vez mais, a academia vem se tornando adepta do pensamento positivo, diretamente ligado à realidade econômica e mercadológica que remete a postura crítica ao mundo das aventuras mentais inúteis. Presa ao discurso científico/tecnológico e fiel às expectativas do modelo instrumental/ utilitarista, a universidade perde a oportunidade de pensar a transcendência 
além-fronteiras comprometida com o humano subjetivo e social. Não responde ao dever de esclarecer à opinião pública a respeito da ocupação do dever ser pelo ser. Deixa de esclarecer o que está acontecendo no cotejamento entre o ser e o dever ser, na perspectiva mais ampla do social e do humano. E, ao fixar-se apenas nas locuções validadas ou validáveis empiricamente, a universidade assume comportamento aparelhado e manipulado, reduz e viola o ser humano e a sociedade atrelando-os à experiência dos fatos sem considerar as ambiguidades e obscuridades dos fatores. Adere à homogeneização sistêmica, escondendo suas contradições, exatamente o ponto de incisão da crítica dialética.

Mas qual é, então, o sentido concreto do pensamento crítico? O pensamento crítico não objetiva construir pontes, curar pacientes ou inventar aparatos tecnológicos. Busca, sim, compreender o mundo, a sociedade e o ser humano; busca, portanto, valorizar o pensamento e a locução que transcendem os limites da validação empírico-operacional. O discurso crítico é o espaço no qual "o pensamento e a linguagem têm permissão para serem legitimamente inexatos, vagos e até contraditórios [como] a maneira mais eficaz de proteger o universo normal da locução de ser seriamente perturbado por ideias impróprias" (MARCUSE, 1973, p. 175).

O olhar empírico da realização técnica se eleva ao patamar de forma única e verdadeira de conhecer e decidir sobre o significado daquilo que é. A linguagem transcendente, ao contrário, considera a verdade não em sua dimensão útil e produtiva, mas em sua relevância para o ser humano e a sociedade. Trata-se, então, não de negar as inegáveis conquistas da ciência e tecnologia, mas de incluir o pensamento transgressor no universo mutilado da locução unidimensional da linguagem científica. O contexto tecnocientífico, ao predefinir a forma sob a qual pessoas e objetos se nos afiguram, determina a validez de suas representações, favorecendo o pensamento unidimensional adequado ao projeto histórico hoje em curso. Fortalecido nas teias do poder, tal projeto se hegemoniza e se impõe como verdade histórica, única e sem alternativa. A solidificação sistêmica favorecida pela eficiência da sociedade tecnológica conecta os polos opostos do progresso e da barbárie, impedindo a modificação qualitativa. Por mais evidente que seja o caráter ambivalente da tecnociência, os interesses econômicos difundem a falsa ideia de que a própria ciência superará os problemas que gera.

Talvez a universidade devesse se colocar com radicalidade e persistência a pergunta a respeito do acontece com o pensamento. O que significa fazer hoje a experiência do pensamento? Lembrando o título da obra organizada 
por Adauto Novaes (2010, p. 10) Mutações - a experiência do pensamento, do ponto de vista da educação superior, seria pensar o mundo dominado pela tecnociência: "é certo que o espírito produziu uma aventura para a qual nem ele mesmo consegue produzir os limites e abrir espaço para o trabalho do pensamento". Vivemos na era da mutação científica em que preside "o elogio dos fatos e dos acontecimentos técnicos, e, principalmente, o elogio do presente eterno, sem passado nem futuro. Tudo se torna veloz, volátil e efêmero".

A privatização no Brasil do espaço público conduz ao individualismo e utilitarismo sem limites frente ao que a tradição imaginava ter consagrado como princípios transcendentes e universais do agir. O exercício da cidadania na vida pública torna-se um discurso opaco e vazio diante do apelo do econômico. A própria vida virou mercadoria sem qualidade, breve e sofrida para os marginalizados; longa e confortável, porém igualmente inócua, para os privilegiados. Prevalece o elogio dos fatos e eventos técnicos na ilusão do presente eterno, veloz, volátil e efêmero. Sobre esta base se organiza a educação superior, limitada à transmissão de conhecimentos úteis e instrumentais. Rompe-se a arquitetura do pensar e instala-se o preceito da tecnociência que reduz o espírito à sua dimensão científica.

Ciência e tecnologia transformam-se em autoridade última diante da qual se assume uma espécie de servidão voluntária, como dizia La Boéthie. A revolta de Nietzsche contra o jugo da moral também nos serve de exemplo para uma nova consciência da dominação do fatual, pela qual nos tornamos alienígenas de nós mesmos. Ao mesmo tempo em que o domínio do puramente operacional nos impede de pensar, não nos resta outra alternativa senão a experiência do pensamento. Adorno (1995, p. 148) nos lembra:

O defeito mais grave com que nos defrontamos atualmente consiste em que os homens não são mais aptos à experiência, [porque] interpõem entre si mesmos e aquilo a ser experimentado aquela camada estereotipada a que é preciso se opor.

A camada estereotipada à qual se refere o Adorno é a matemática do instrumental, princípio fundamental do pensamento contemporâneo que media tudo, impedindo-nos de fazer a experiência imediata da realidade. Pensar, diz o filósofo, é o mesmo que fazer experiências intelectuais. Hannah Arendt (2009, p. 41, 32) complementa dizendo que vivemos hoje uma exasperação apaixonada contra a razão porque o pensamento se apartou da realidade. "Meu pressuposto é que o próprio pensamento emerge de incidentes da experiência viva e a eles deve permanecer ligado, já que são os únicos por onde pode ob- 
ter orientação". Vivemos hoje uma "exasperação apaixonada contra a razão" porque "o pensamento se apartou da realidade", deixando a realidade opaca à luz do pensamento.

O pensamento puramente operacional concentra-se nos experimentos e abole a experiência. Experiência significa ter a percepção dos problemas e fazer o trabalho do pensamento, desvelando as formas históricas da razão, seus fluxos, remansos e refluxos. Fazer a experiência do pensar é, pois, suspeitar das locuções do real, da lógica do pensamento puramente instrumental que hoje nos enquadra e condiciona. É arriscar-se a admitir que a objetividade das provas não deve ser o limite do humano, nem seu descanso final. É o trabalho do espírito que ultrapassa a velocidade da reprodução técnica. "Nossa realidade", lembra Novaes (2010, p. 17), "pode ser definida pela velocidade da reprodução técnica, o que leva o pensamento a estar sempre a reboque dos acontecimentos".

Disso decorre, em termos de educação superior, a primazia do valor instrumental do homem fragmentado entre os recortes caleidoscópicos das disciplinas acadêmicas que, dentro do tubo do pensamento instrumental, se revolvem e ajeitam ao sabor dos movimentos estratégicos do mercado. $\mathrm{O}$ mercado faz as vezes de uma nova transcendência que, além e externa ao humano, limita sua liberdade e o inclui no manejo do todo. A lógica tecnocientífica comete a pretensiosa desmesura de reduzir a atividade do espírito à descoberta e aplicação das regularidades do empírico com vistas ao seu uso estratégico no mundo da produção e do mercado.

Só o espanto intuitivo da liberdade espiritual é capaz de romper a barreira da legitimação objetivista do real e abrir espaço para o entendimento crítico da forma que a tecnociência deu ao mundo. Em A evolução criadora, Henri Bergson (2010, p. 214-215) tenta libertar a inteligência de sua circularidade realista instrumental: "É preciso precipitar as coisas e graças a um ato de vontade, conduzir a inteligência para fora dela". É o pensamento que deve decidir dar este salto. "Em teoria", sempre segundo Bergson, "é uma espécie de absurdo ter um conhecimento que não seja dado pela inteligência; mas se aceitarmos corajosamente o risco, talvez a ação corte o nó que o raciocínio deu, e que ele não desatará". A atitude do pensamento em relação ao vivo "não poderia ser a mesma da ciência, cujo objetivo é agir" e que, por esta razão, encara somente sob este aspecto a realidade restante. Quando se encaixa no mesmo quadro as duas realidades, "erigindo em absoluto a unidade fictícia da ciência", "sente-se estalar a moldura". O pensamento humano não pode ser reduzido ao conhecimento científico. 
O espanto é a suspensão da explicação mecânica para tudo o que acontece no mundo dominado pelo valor mercantil para poder reinventar e redefinir o mundo em talhe humano. O nosso mundo é invadido por novos problemas e perplexidades com os quais somos incapazes de lidar a partir de nossos conceitos tradicionais, formulados na lógica cientificista instrumental moderna. Mas, ao mesmo tempo, somos impedidos de fazê-las pelo modelo de formação instrumental hoje prevalente. Segundo Hannah Arendt (2009, p. 96),

há uma fatídica monstruosidade nos processos invisíveis [que] engolfaram todas as coisas tangíveis e todas as entidades individuais visíveis para nós, degradando-as a funções de um processo global. [...] O processo que torna por si só significativo o que quer que por ventura carregue consigo, adquiriu assim um monopólio de universalidade e significação.

Esta fatídica monstruosidade de um processo que torna significativo tudo o que carrega consigo já era o que Sócrates mais temia e tentava impedir na polis. Por isso, gerava espanto em seus interlocutores forçando-os a pensar. Talvez hoje se necessite fazer o mesmo com o cientificismo e as 'superstições' que permeiam todo o projeto educativo. Em tempos de racionalidade técnica, a experiência do pensamento atento às dimensões íntimas das coisas cede lugar à mecânica instrumental do poder, do descrever, medir e calcular. O pensamento posto a serviço do progresso científico-tecnológico não serve mais ao esclarecimento inerente ao projeto da universidade moderna. Por isso, talvez assista razão a Bergson quando este diz que é necessário um gesto de vontade. Este gesto deve ter algum ponto de partida.

No próximo item quero sugerir que a formação docente pode ser uma das estratégias de contraposição ao fetiche do método científico que apenas explica, prescreve e funciona. Uma possibilidade de recomposição da experiência que ultrapasse os limites do funcional e se abra ao sentido humano individual e coletivo.

\section{FORMAÇÃO DOCENTE}

Demos até aqui dois passos. Primeiro vimos, em perspectiva histórica, a evolução da educação superior, constatando que, a partir da modernidade e, mais fortemente, ao longo da segunda metade do Século passado, a universidade tornou-se agente do desenvolvimento científico tecnológico. Aos poucos, a educação superior abandonou seus ideais formativos, integrando- 
-se, em termos de pesquisa e ensino, ao grande movimento da tecnociência em prejuízo de sua autonomia no pensar. Num segundo movimento, tentei esclarecer um pouco o que significa o pensar no presente contexto. Pretendo agora avançar algumas ideias a respeito do sentido destas considerações para a prática pedagógica na educação superior.

Consoante ao exposto acima, Adorno e Horkheimer (1985, p. 129) são categóricos ao afirmar que com "a vitória da razão tecnológica sobre a verdade [...] o pensamento é ele próprio massacrado e despedaçado". Esta convicção leva Adorno (1995, p. 60) em seu trabalho Educação e Emancipação a afirmar que "a verdadeira formação do espírito, [é] o objetivo das escolas superiores”. A formação do espírito seria, portanto, o sentido maior da educação superior. A realização deste ideal implica, na verdade, repensar a universidade em termos de seu papel nos campos da pesquisa e do ensino, no contexto do mundo célere, tecnocientífico, economicizado e instrumental contemporâneo. Responsabilidade de ofício da universidade, cabe a ela a tarefa de repensar seu papel no contexto das tensões e ambivalências na chamada sociedade do conhecimento. Três pontos me parecem essenciais a esta responsabilidade: avaliar o sentido e o modo de atuar da universidade na sociedade atual; redimensionar a estrutura curricular numa perspectiva formativa e transdisciplinar; e assumir como central a formação docente. No que segue, destaco este último ponto para uma breve reflexão.

Recorro mais uma vez a Adorno, agora para introduzir o conceito de Bildung, a meu ver, ainda hoje relevante, embora careça de sempre novas interpretações, nos diferentes contextos sociais e culturais. Diz o autor (1995, p. 63):

A colcha de retalhos formada de declamação ideológica e de fatos que foram apropriados, isto é, na maior parte das vezes decorados, revela que foi perdido o nexo entre objeto e reflexão. A constatação disso nos exames é recorrente, levando imediatamente a concluir pela ausência da formação cultural (Bildung) necessária a quem pretende ser um formador.

Na passagem em destaque, Adorno refere-se à história de uma estudante, candidata ao magistério, que queria ser examinada na prova oral de filosofia sobre o filósofo Henry Bergson. O examinador, querendo saber se ela tinha noção do contexto histórico-cultural de seu autor/tema, perguntou-lhe a respeito de pintores da época de Bergson, de alguma forma, relacionados com o espírito de sua filosofia. Não obtendo resposta, o examinador concluiu que a estudante também não poderia ter entendido Bergson. 
$\mathrm{Eu}$ mesmo, numa disciplina de licenciatura em física numa renomada universidade pública brasileira, perguntei aos alunos o que sabiam de Isaac Newton e o sentido histórico de suas teorias. A pergunta me parecia relevante porque contexto histórico-cultural certamente nos revela muito a respeito da própria disciplina. Ninguém quis responder. No entanto, todos conheciam um sem número de teorias e fórmulas físicas. Este relato não teria maior importância não fosse o fato que os estudantes eram alunos de licenciatura e, portanto, candidatos ao magistério. Tinham bons conhecimentos em física, mas pouco sabiam disto que Adorno chama de 'formação cultural', na sua opinião, necessário a quem pretende ser um formador.

Desolador é constatar a indiferença dos alunos com relação a estas questões. Daí a pergunta que Adorno (1995, p. 64) coloca na sequência de seu relato:

Mas se fôssemos confrontados com a questão de como afinal é possível adquirir esse tipo de formação cultural, que permite associar Bergson ao impressionismo, isso traria perplexidade [...] porque a formação cultural é justamente aquilo para o que não existem à disposição hábitos adequados; ela só pode ser adquirida mediante esforço espontâneo e interesse, não pode ser garantida simplesmente por meio da frequência de cursos $[\ldots]$.

A formação cultural requer interesse, dedicação, amor e "quem tem deficiências a este respeito [seria melhor] não se dedicasse a ensinar" complementa o autor. $\mathrm{O}$ conhecimento técnico ou científico não substitui a reflexão intelectual, a formação cultural (Bildung), luz indispensável para a atuação apropriada e segura na prática pedagógica.

Talvez antecipando-se à habitual praticidade, Adorno (1995, p. 141) adianta que a solução evidentemente não é a assim chamada

modelagem das pessoas, porque não temos o direito de modelar as pessoas a partir do seu exterior; mas também não a mera transmissão de conhecimentos, cuja característica de coisa morta já foi por demais destacada, mas a produção de uma consciência verdadeira.

No contexto, consciência verdadeira significa pensar a realidade em perspectiva mais ampla o ser humano, o mundo e o ser humano no mundo, tematizando pontos nevrálgicos, tabus e contradições. Em outras palavras, significa envolver as precedências sistêmicas da contemporaneidade, focadas no conhecimento científico-tecnológico de corte instrumental-utilitarista, nas pre- 
cedências do humano e do social. A relação entre conhecimento e pensamento, nos termos acima discutidos, devem ser parte constitutiva do mesmo processo formativo. Para que isto ocorra no espaço da educação superior e da educação em geral, a formação docente deve contemplar estas duas dimensões. Sendo a educação superior responsável tanto pela formação de docentes do ensino básico e superior, depreende-se que esta mudança de perspectiva poderá trazer qualidade nova ao processo formativo.

Romper este movimento circular entre educação e sistema, certamente, não é tarefa simples e linear uma vez que, segundo a ideia corrente, espera-se dos docentes exatamente o agir competente e consoante ao processo civilizatório, vale dizer, que preparem pessoas competentes e funcionais, em termos das expectativas do mercado. Sabe-se que, enquanto o sistema gera a barbárie a partir de si mesmo, a educação tem apenas condições relativas de mudar esta situação. Num contexto em que os conhecimentos são mercadorias, os alunos clientes, os professores agentes de um processo mercantil, como esperar deles o salto ao patamar da reflexão crítica? De fato, o sistema aparenta densidade instransponível.

Na medida em que a razão técnica ganha espaço, explica Habermas (1997, p. 51-52), a racionalidade instrumental sistêmica assume as funções de sujeito histórico submetendo a universidade ao sistema produtivo. Assim, a universidade fecha o "círculo funcional da ação instrumental", tornando remota a possibilidade de romper os ferros do "círculo funcional da ação controlada pelo êxito que unifica a decisão racional e a ação instrumental". No interior da universidade, as decisões relativas ao planejamento curricular, à criação de novas disciplinas e projetos de pesquisa e estudo se orientam crescentemente no interesse instrumental. Inclusive as instituições de fomento consideram esta variante como critério importante para a concessão de recursos.

Este é o círculo vicioso cada vez mais difícil de ser rompido. Pelo que vemos, a universidade não resiste à pressão adaptativa de ajustar-se às regras da gramática da racionalidade instrumental. O sangue que circula nas veias do próprio Estado está contaminado por esta mentalidade instrumental/economicista tornando contamina as instituições públicas. Relativizam-se, assim, as críticas maniqueístas que atribuem todos os males do sistema de educação superior à privatização. Se bem é verdade que o mundo de hoje se move pelo desejo do lucro e da ganância e o ensino superior virou uma espécie de loja de venda de diplomas a prestações nas instituições privadas onde se encontram $70 \%$ dos estudantes universitários, é simples demais pressupor que as instituições públicas e comunitárias estejam livres desse mal. Ao contrário, cres- 
centemente elas vêm se transformando num 'quase-mercado' ou 'capitalismo acadêmico', conforme anota Dias Sobrinho (2005, p. 138).

Os interesses econômicos definem de tal modo o sistema social como um todo que as instituições são coagidas a atendê-los, sob pena de serem consideradas extemporâneas e sem conectividade social. O crescimento econômico enquanto bem supremo e a ciência/tecnologia como seu principal provedor se encarnaram de tal modo na lógica da evolução do progresso social que dispensam hoje qualquer discussão pública. A legalidade lhe é supostamente imanente, acima, portanto, de qualquer validação social e ética. Do ponto de vista da educação superior, o sistema se impõe como suave dominação ideológica à qual os professores e alunos docilmente se acomodam. Ciência e tecnologia, como telos da vida social e individual, invadem todos os espaços, incluindo aqueles, a exemplo da universidade, que deveriam ser bastiões de negação e resistência.

Muitas vezes alimentamos a esperança que a área das ciências humanas teria a possibilidade de assumir, por assim dizer, um "sherifado" crítico ou ético no campo da ciência e tecnologia. Comentando um texto de Aldous Huxley (1966) em que este atribui à literatura uma perspectiva crítica em relação aos rumos da ciência, Habermas (1997, p. 95) argumenta que a relação imediata entre as duas culturas (literatura e ciência) lhe parece um mal-entendido porque o conteúdo informativo das ciências só adquire sentido prático ou ético no momento em que se explicitam as consequências práticas do progresso científico. Ou seja, a ciência, enquanto neutra e pura, não tem sentido ético e, portanto, seria indiferente ao mundo vital/ético da literatura ou das ciências humanas. Os conhecimentos da física atômica, p. ex., permanecem sem consequências para o mundo social enquanto não forem realizadas fissões nucleares, evidenciando suas consequências práticas, produtivas ou destruidoras, decisivas para a consciência reflexiva do mundo vital. Para que a relação entre literatura seja produtiva em termos de humanização seria necessário, sempre segundo Habermas, que a literatura assumisse os enunciados científicos para dar-lhes uma figura de sangue e carne. Por meio desse desvio, se configura, assim Habermas (1997, p. 96), "o problema de como é possível a tradução do saber tecnicamente utilizável para a consciência prática do mundo social da vida". E o autor conclui:

esta desproporção de duas culturas é alarmante só porque, na aparente disputa de duas tradições espirituais em concorrência, se perfila verdadeiramente um problema vital de civilização configurado pela 
ciência: o problema de como se pode hoje efetuar a reflexão sobre a conexão, ainda espontânea, entre o progresso técnico e o mundo social da vida, e submetê-la aos controles de uma discussão racional.

Em suma, a renúncia ao atual modelo de ciência e tecnologia em favor de outro qualitativamente diferente, sugerida por muitos críticos, parece bastante remota. O que sim se pode imaginar, e ambientalistas já colocam isso em perspectiva, é a humanização da relação entre ciência/tecnologia e natureza/sociedade, conferindo-lhe características menos dominadoras e mais fraternais, menos colonizadoras e mais dialógicas. Nas palavras de HABERMAS (1997, p. 53) "em vez de natureza explorada, podemos buscar a natureza fraternal" [...] limitando-nos a "trabalhá-la com rotura de comunicação".

A centralidade da ciência e tecnologia exige uma discussão racional que ultrapasse o patamar da tecnicidade instrumental e alcance a transformação do saber técnico em consciência. Trata-se da inserção dos meios técnicos nos contextos sociais e éticos. Para isso, a relação intrínseca entre conhecimento, formação e transformação, ainda presente no contexto pré-industrial de Humboldt, hoje já não se sustenta.

Admitindo como justificada a desconfiança habermasiana a respeito da relação causal e mecânica entre a formação privada de indivíduos e a superação dos riscos decorrentes dos avanços científico-tecnológicos, é preciso ter em conta que, no caso da universidade, se trata de uma instituição diretamente envolvida na produção e difusão da ciência e tecnologia. É de supor, portanto, que os agentes desse processo, ou seja, docentes e alunos, possam contribuir para a formação de uma nova consciência prática e crítica na esfera política do contexto do mundo da vida.

Bem sei que os ponteiros não apontam para este norte. É preciso reconhecer também que ideia, ainda válida no século XIX, de que a ciência forma, já não se aplica na sociedade industrial contemporânea na qual os processos de investigação e de formação se vinculam diretamente à transformação técnica e sua utilização econômica. As universidades, agora comprometidas com a formação profissional e a produção de conhecimentos economicamente interessantes, fecham o circuito entre produção/difusão de conhecimento e utilização prática, livre de quaisquer critérios éticos ou formativos referenciados ao humano e social. Na medida em que a ciência se orienta no interesse instrumental, abandona seu potencial formador.

Hoje as ciências se transformaram em poder técnico de domínio e exploração da natureza e do homem. Este poder de disposição que as universidades ensinam não se associa ao desenvolvimento da capacidade de pensar e 
agir eticamente. Se outrora "as experiências científicas se podiam interpretar e transformar em capacidades práticas, isto é, numa consciência reflexiva do praticamente necessário" (HABERMAS, 1997, p. 99) hoje o conhecimento científico já não gera transformações éticas. Não há, portanto, uma relação entre o domínio do conhecimento das ciências empíricas e a transformação ética/prática.

No entanto, este não é necessariamente o final de uma história. Diante dos riscos de seu uso para o homem e a natureza, a ciência se vê hoje novamente diante do desafio, premente e urgente, de repensar a dimensão ético/prática. As comissões de ética, instaladas em todas as universidades que praticam ensino e pesquisa, são um claro sinal da necessidade de uma reorientação ética da ciência. Esta é uma nova tarefa da formação acadêmica no marco de uma sociedade abalada pelos riscos potenciais da ciência e tecnologia, dos quais nos falam Postman (1994), Mattéi (2002), Beck (2006), Henry (2012) e tantos outros.

É de Heidegger a famosa expressão "a ciência não pensa". O filósofo queria dizer que os métodos da ciência não dão acesso ao sentido. Efetivamente, mesmo elevada ao patamar de uma quase-metafísica, supostamente capaz de explicar tudo e livrar o homem de toda pena e dor, a ciência é no mínimo corresponsável pela extensão da recente história de barbárie e destruição. Mesmo sendo "tudo arremetido à aridez dos números, à aspereza dos sentidos e à arrogância intelectual do imediato", (NOVAES, 2010, p. 25), a ciência não se livra da suspeita dos efeitos ambíguos, tanto em relação ao progresso quanto ao regresso da civilização contemporânea.

O poder de disposição técnica, inicialmente exercido sobre a natureza, estende-se hoje, também, diretamente ao ser humano e à sociedade. Por esta razão, os avanços científico-tecnológicos e a estupenda ampliação do poder de intervenção não dispensam mais o ordenamento do agir ético. Pode-se concluir daí que é profundamente suspeita a formação acadêmica que separa o domínio científico-tecnológico da formação da consciência ético-prática. Ambas as dimensões precisam ser pensadas conjuntamente desde sua raiz. Isto coloca a universidade frente à enorme e inarredável tarefa de pensar a inovação científico-técnica na perspectiva de suas implicações éticas, as quais já não podem ser ignoradas, pelo menos se desejarmos vida longa para o mundo e a humanidade.

Para isso, na expressão de Habermas (1997, p. 105), importa "pôr em andamento uma discussão politicamente eficaz que consiga pôr em relação, de um modo racionalmente vinculante, o potencial do saber e poder técnicos com o nosso saber e querer práticos." 
A universidade, enquanto instituição afeita tanto ao desenvolvimento do conhecimento científico-tecnológico quanto à formação de profissionais, que, de uma ou de outra forma, exercem liderança social, parece ser a instituição mais indicada para, de um lado, institucionalizar internamente e, de outro, fomentar o debate público destas questões. A universidade não sofre pelo excesso de ciência e técnica por que já que elas, efetivamente, promovem conforto e bem-estar. A universidade sofre, sim, da falta de pensamento crítico que alcance os espaços humanos e sociais, que ciência e tecnologia sozinhas não alcançam.

Os professores precisam saber e os estudantes aprender que a ciência implica um nó insondável que nenhuma teoria pode explicar ou resolver por inteiro. De outro lado, é preciso saber que os avanços da ciência empurram diante de si, dando-lhe sempre novos contornos, o insondável do qual só o pensamento consegue se ocupar. O pensamento é indefinível, livre e imprevisível; o pensamento não pensa para isso ou aquilo, para esse ou aquele; o pensamento pensa em nome da humanidade, da transcendência. Esse é um dos principais desafios da universidade hoje cuja solução passa pela transformação dos indivíduos, seus elementos constituintes. A formação é, pois, possibilidade e condição essencial da luta contra a barbárie. Quanto menores e mais limitadas forem as chances de mudar os pressupostos objetivos que fomentam a barbárie, mais importante se torna a estratégia da formação dos sujeitos. A formação de professores não pode ficar fora desta agenda. Adorno (1995, p. 121) é radical: "a educação tem sentido unicamente como educação dirigida a uma auto-reflexão crítica".

\section{CONCLUSÃO}

O objetivo que me propus no início deste ensaio foi desenvolver três argumentos: primeiro, mostrar que a universidade percorreu uma trajetória, ao final da qual ela se tornou uma instituição aderente ao sistema hoje dominante; segundo, tendo em vista a supremacia da ciência/tecnologia e suas estratégias, argumentar a favor de uma consciência crítica; e, finalmente, defender a importância da formação docente como estratégia de incremento de uma nova postura crítica.

Quanto ao primeiro aspecto espero ter conseguido esclarecer, de algum modo, o percurso da universidade que, no início de sua história, ainda estava presa ao modelo medieval de verdades metafísicas e transcendentais que assumia transmitir e explicar racionalmente. Com o surgimento do modelo 
de racionalidade moderna, concretizado, inicialmente, fora da universidade, ela passou, a partir do Século XVIII e mais fortemente no Século XIX, a associar o conhecimento ao sentido social, adensado no ideal da Bildung por Humboldt, no famoso modelo da universidade alemã. Por último, associou-se ao ímpeto do desenvolvimento científico-tecnológico que prometia realizar o grande ideal moderno, salvando o homem pelo uso da razão.

No segundo movimento, apoiado em diversos autores, especialmente do redil da teoria crítica, argumentei que a universidade, na medida em que se torna aderente aos ditames da racionalidade científico-tecnológica, vestiu os trajes do sistema, tornando-se uma instituição dedicada à produção e difusão do conhecimento. Em seu interior, o debate entre os interesses sistêmicos de corte sistêmico/mercadológico e os objetivos culturais/humanistas, foi sendo decido em favor dos primeiros.

Finalmente, espero ter tornado plausível a ideia de que a formação docente pode ser um caminho para colocar novamente em pauta o debate do sentido social do processo de ensino e pesquisa no interior da universidade. Seria este um novo modelo de formação que, incorporando ciência e tecnologia, prioriza o sentido humano e social da educação superior.

\section{REFERÊNCIAS}

ADORNO, Theodor. Educação e emancipação. Rio de Janeiro: Paz e Terra, 1995.

ADORNO, Theodor; HORKHEIMER, Max. Dialética do esclarecimento. Rio de Janeiro: Jorge Zahar, 1985.

ARENDT, Hannah. Entre o passado e o futuro. São Paulo: Perspectiva, 2009.

BECK, Ulrich. La sociedadad del riesgo: hacia una nueva modernidad. Barcelona: Paidós, 2006.

BERGSON, Henri. A evolução criadora. São Paulo: UNESP, 2010.

BRANDT, Reinhard. Wozu noch universitäten? Hamburg: Felix Meiner Verlag, 2011. 
DIAS SOBRINHO, José. Dilemas da educação superior no mundo globalizado: sociedade do conhecimento ou economia do conhecimento. São Paulo: Casa do Psicólogo, 2005.

HABERMAS, Jürgen. Técnica e ciência como ideologia. Lisboa: Edições 70, 1997.

HENRY, Michel. A barbárie. São Paulo: É Realizações, 2012.

HUXLEY, Aldous. Litterature and Science. Praxis, n. 112, p. 1217-1228, 1966.

KANT, Immanuel. O conflito das faculdades. Lisboa: Edições 70, 1993.

MATTÉI, Jean-François. A barbárie interior: ensaio sobre o i-mundo moderno. São Paulo: UNESP, 2002.

MARCUSE, Herbert. A ideologia da sociedade industrial: o homem unidimensional. Rio da Janeiro: Zahar, 1973.

NOVAES, Adauto. Mutações: a experiência do pensamento. São Paulo: Edições Sesc, 2010.

PEREZ LINDO, Augusto. Políticas del conocimiento, educación superior y desarrollo. Buenos Aires: Editorial Biblos, 1998.

POSTMAN, Neil. Tecnopólio: a rendição da cultura à tecnologia. São Paulo: Nobel, 1994. 